\title{
Imagem sem imagens
}

\section{Resumo}

Como se aprende? O que é uma imagem sem imagens? Estas questões são o ponto de partida para o estudo das relações das imagens com a aprendizagem. Propomo-nos a pensar que a aprendizagem não pode ser feita sem uma unidade de conexão, um processo criador virtual-atual. Aprender é uma "tarefa infinita" e transformadora dos movimentos do corpo, do pensamento e do espaço-tempo conjugados, que exige um encontro concreto feito de uma "familiaridade prática" experimental. Este é o objeto da nossa análise: a imagem enquanto operação, transformadora prática de energias, que agem na educação, no quotidiano, no mundo.

Palavras-Chave: Imagens; aprendizagem; educação.

\section{Résumé}

Comment apprendre? Qu'est-ce qu'une image sans images? Ces questions sont le point de départ pour l'étude des relations des images avec l'apprentissage. Nous soutenons que l'apprentissage ne peut se faire sans une unité de connexion, sans un processus de création virtuelle-réelle. L'apprentissage est une «tâche infinie» qui peut transformer les mouvements du corps, de la pensée et de l'espace-temps conjugués. Il exige une rencontre concrète qui implique une «familiarité pratique" expérimentale. Tel est l'objet de notre analyse: l'image comme opération, pratique transformatrice d'énergies qui agissent dans l'éducation, dans la vie quotidienne et dans le monde.

Mots clés: Images; apprentissage; éducation. 
$\mathrm{H}$

ipótese um: “A aprendizagem não se faz na relação da representação

com a acção" (DELEUZE,1968, p.73).

\section{Ponto prévio:}

Referimo-nos nesta análise aos conceitos de imagem e aprendizagem de modo genérico, compreendendo as limitações que daí resultam. A nossa hipótese, no entanto, desenvolve-se tendo em conta algumas das possíveis implicações destes conceitos um no outro e as implicações de ambos, na educação, nas artes e no quotidiano.

\section{Desenvolvimento da hipótese:}

1. A aprendizagem far-se-á numa relação particular de uma imagem entendida como um movimento livre, real, rítmico, afectivo e vital - com um conjunto de movimentos corporais, próprios de um corpo intensamente vivo. Esta relação, este encontro, é a condição que permite fazer a diferença na vida, no corpo e no pensamento. Aprende-se quando se conjugam "pontos relevantes do nosso corpo" com "multiplicidades de fulgores" elementos últimos, desconhecidos e inesperados, da natureza, que coexistem e habitam imperceptíveis em todos os lugares e instantes. Estes últimos, quando irrompem, trazem, porque transportam, o que é iminentemente novo. Aprender é uma "tarefa infinita" e transformadora dos movimentos do corpo, do pensamento e do espaço-tempo conjugados. Tarefa dinâmica e positiva que na sua novidade age sem cessar no continuum da vida.

Uma imagem é neste sentido, ela mesma, uma multiplicidade criadora - é uma unidade de base para outras imagens - que conjuga elementospartículas heterogêneos e constitui o plano vital que age e se envolve na aprendizagem entretecendo os devires necessários (por exemplo, entre o nadador e a onda). Entre o corpo e a onda forma-se uma imagem sem

Filosofia e Educação [rfe] - volume 8, número 1 - Campinas, SP

Fevereiro-Maio de 2016 - ISSN 1984-9605 - p. 26-37 
imagem, feita de puras virtualidades, sensações, forças afectivas e desejos que conectam a onda ao corpo e o corpo à onda. A imagem é virtual porque antecipa as conexões entre o corpo e a onda, traçando o diagrama das suas atualizações possíveis. As relações espaço-temporais vão mudar, a intensidade dos afectos, os movimentos vitais das forças em jogo desterritorializam-se, traçam-se novas linhas de fuga criadoras. A imagem, aprende-se e apreende-se a si mesma com os elementos que a compõem, com as forças que a tornam viva e sensível. Aprende-se a nadar. Imagem e aprendizagem são uma só.

Dizemos que os elementos que compõem estes dois conceitos são virtuais "na medida em que a sua emissão e absorção, e a sua criação e destruição se fazem num tempo mais pequeno do que o mínimo de tempo contínuo pensável, e que esta brevidade os mantém desde logo sob um princípio de incerteza ou de indeterminação" (Deleuze, 1996, p.179, tradução nossa). "Aquilo a que chamamos virtual não é algo ao qual falte realidade, mas que se envolve num processo de actualização ao seguir o plano que lhe dá sua realidade própria" (Deleuze, 2003, p. 363, tradução nossa).

Chamamos então a esta imagem singularidade virtual-atual com realidade própria, sempre em devir, sempre criadora. Vinda de uma espécie de espaço liso, feita de afectos que nada delimitam, figuram ou imitam. Sem forma nem fundo, nem fora nem dentro, começo ou fim. Estas imagens são multiplicidades impossíveis, inclassificáveis e sempre agindo na aprendizagem. Impossíveis potências de expressão de uma "intensa vida germinal inorgânica". Que forças as atravessam e que forças específicas advêm delas e as desencadeiam no seu envolvimento com a aprendizagem? Na verdade, que imagens são estas? 
O nadador e a onda dispõem-se numa elasticidade variável e conjugam-se, num momento particular e desconhecido, sem sujeito nem objeto, os gestos tornam-se livres e vitais - aprende-se a nadar porque se deseja nadar. Os corpos dispõem-se para intensificações, vindas de sensações mínimas, que violam as fronteiras habituais, do pensamento, do saber, do conhecimento, de aprendizagens anteriores estabelecidas, sedimentadas e estratificadas. Dispõem-se para circuitos inabituais, áridos, insólitos... grandes e pequenos circuitos.

Entre o nadador e a onda e com os dois prepara-se e ajusta-se qualquer coisa nova e consistente. Um e outra não serão mais os mesmos, infinitas micro-partículas, de ambos, agenciam-se com. Vejam-se os exemplos de Deleuze:

a) "Se aprendo a nadar, ou a dançar, é preciso que meus movimentos e meus repousos, as minhas velocidades e as minhas lentidões tomem um ritmo comum com os do mar, ou do parceiro, segundo um ajustamento mais ou menos durável” (Deleuze, 1993, p. 192, tradução nossa).

b) “Aprender a nadar, aprender uma língua estrangeira, significa compor os pontos singulares do seu próprio corpo ou da sua própria língua com os de uma outra figura, de um outro elemento que nos desmembra, que nos leva a penetrar num mundo de problemas até então desconhecidos, inauditos. E a que estaríamos destinados senão a problemas que exigem até mesmo a transformação do nosso corpo e da nossa língua?” (Deleuze, 1968, p. 317).

c) "Nunca se sabe como uma pessoa aprende; mas, de qualquer forma que aprenda, é sempre por intermédio de signos, perdendo o seu tempo, e não pela assimilação de conteúdos objetivos. Quem sabe como um estudante pode tornar-se repentinamente "bom em latim", que signos (amorosos ou até mesmo inconfessáveis) lhe serviram de aprendizagem? Nunca aprendemos

Filosofia e Educação [rfe] - volume 8, número 1 - Campinas, SP

Fevereiro-Maio de 2016 - ISSN 1984-9605 - p. 26-37 
nos dicionários que os nossos professores ou os nossos pais nos emprestam. O signo implica em si a heterogeneidade como relação. Nunca se aprende fazendo como alguém, mas fazendo com alguém, que não tem relação de semelhança com o que se aprende. Quem sabe como se tornar um grande escritor? (Deleuze, 1996, p. 31-32, tradução nossa).

A relação, esta relação de singularidades e entre singularidades, extrai qualquer coisa de novo das ressonâncias entre-dois que, paradoxalmente, se fazem inconscientemente e "fora dos eixos", porque ninguém sabe como aprende. Entre o não saber nadar e o bruscamente saber há uma espécie de "vazio" "entre" que se mantém de alguma maneira sempre intraduzível como as "imagens virtuais na medida em que a sua velocidade ou a sua brevidade as mantém aqui sob um princípio de inconsciência” (Deleuze, 1996, p.180). Aprender é uma "passagem viva" de um estado de "entre" para outro "com". Uma passagem que une sem mediatizar e não deixa de ser singular. Mesmo que nada possamos saber dela, como não sabemos das imagens, quando aprendemos, porque "o movimento do nadador não se assemelha ao movimento da onda", construímos um encontro cúmplice, para lá da natureza, imanente, num certo plano de composição do desejo. Ou, como diz Deleuze mais uma vez: "Eis porque é tão difícil dizer como é que alguém aprende". Tão difícil de dizer e ver, mas no entretanto aprendese. E, nada se pode dizer de antemão, não há limites bem definidos nem adjetivos adequados para se poder antecipar.

2. Há, para Deleuze, uma "familiaridade prática" "que faz de toda a educação algo de amoroso, mas também mortal" e que não se deixa esgotar, nem engolir, nem capturar, quer dizer, representar. Não há método para aprender como não há para encontrar tesouros. Mas essa "passagem viva", no vazio (entre-dois), acontece por uma "familiaridade prática" de

Filosofia e Educação [rfe] - volume 8, número 1 - Campinas, SP

Fevereiro-Maio de 2016 - ISSN 1984-9605 - p. 26-37 
“conjugação e dissociação de fluxos". Para dizer o que é tão difícil, como Deleuze bem viu, tentamos analisar esta "familiaridade prática" inimaginável enquanto imagem sem imagem ou singularidade de um "espaço liso" a construir.

A "familiaridade prática" é a conjugação que o corpo é capaz de fazer ("fazer com") quando une sem unir, sem imitação ou identificação, os "seus pontos notáveis com os da onda" e "estabelece o princípio de uma repetição, que não é a do Mesmo, mas que compreende o Outro, que compreende a diferença e que, de uma onda e de um gesto a outro, transporta esta diferença pelo espaço repetitivo assim construído" (Deleuze, 1968, p. 7374). É capaz, pois, de integrar a mais pequena diferença (o Outro) e de percorrer todos os espaços-tempos, na maior velocidade ou lentidão e até na mais pequena imobilidade. E o que a percorre é, numa palavra, o afecto, melhor, a força dos afectos. Capazes eles mesmos, dada a sua natureza processual, de percorrerem os extremos, ultrapassarem os códigos e irem para lá da subjetividade e dos objetos dados, para zonas de intensidade variável. A "familiaridade prática" entrelaça-se numa cultura de afectos e vive dela, experimenta e experimenta-se. Um aluno numa sala de aula em silêncio sossegado (num "não-fazer" que é um fazer ou um "desfazer”) ou na maior perturbação, no mais violento desassossego é atravessado por esta familiaridade, que o faz aprender, que o faz desejar existir. O seu corpo é tanto biológico como coletivo, político, ético ou estético. É um corpopensamento em devir.

Estamos mesmo vendo a dificuldade desta "familiaridade" tão pouco familiar, destas imagens e desta aprendizagem tão fora dos eixos, tão fora de si, que se opõe às estratificações, às hierarquias e às organizações mais habituais (do campo social, educacional, etc.).

Filosofia e Educação [rfe] - volume 8, número 1 - Campinas, SP

Fevereiro-Maio de 2016 - ISSN 1984-9605 - p. 26-37 
Imagens com o poder familiar de induzir nelas próprias o movimento não pensado, impensável mesmo, que fazem aparecer a aprendizagem e a tornam sensível. Imagens com dupla direção: permitem-se demolir (se) e criar (se). Criar-se autônomas, sem referências, irrepresentacionais e inimagináveis. Não se trata pois de representação, reprodução do real mas de criação ininterrupta de um novo "processo imanente do desejo" - "puro movimento criador de um espaço e de um tempo dinâmicos".

Uma imagem "fora dos eixos", inimaginável, não é uma imagem sem eixos ou com eixos mutilados, constitui-se com todo o poder para com essa "familiaridade prática" (se) transportar para todos os eixos, para todos os estados. Esta imagem, porque temos corpo, "quando o corpo conjuga os seus pontos notáveis com os da onda" é uma imagem a que mal podemos chamar imagem, mas não é por lhe faltar alguma coisa porque nada the falta. A nossa hipótese formaliza-se assim a partir de qualquer coisa efêmera e bastante frágil, sem a qual "não podemos passar" (para usar esta expressão em toda a sua ambiguidade), para construir ou chegar ao processo de abertura de um "espaço" real e concreto sem ter de o representar ou dar-lhe nome ou encontrar lá uma história. E o mais difícil ainda: conseguir manterse e conservar-se aí, inconscientemente, numa "Saúde", numa Vida.

Uma impressão, espécie de pressentimento... esta imagem não se desliga da questão de como construi-la? Como não se desliga de uma certa vida prática e amorosa, de certas visões e audições, do olfacto e dos gestos são tantos os elementos que podem agenciar-se que a tarefa parece infinita.

Que imagens são estas? Algumas qualidades práticas de que se pode falar, parecem "familiares". $\mathrm{Na}$ beira do seu desaparecimento, numa urgência de fuga, entre outras imagens mais fáceis de apanhar, esperam fugazes, não se precipitam, como se sentissem que com elas de uma certa maneira o cosmos muda. Livres, danadas, paradoxais, podendo ser 
unicamente boas, conservam o mínimo da forma, como conservam o mínimo da diferença, são outros mundos. Transportam-se com os desejos, as sensações, os sonhos, os pensamentos, projetam-se na natureza porque são da natureza e já não são, porque são da arte, das ciências, da filosofia, do quotidiano. Imaginam-se. Quer dizer, fazem-se a si próprias desfazendo o mundo ótico. São imagens que diagramatizam. Atravessam sem propósito a aprendizagem, tornam-se reais enquanto se aprende e desaparecem no resultado. O nadador sai da água e quererá sempre voltar. Nunca serão as mesmas imagens a que se volta, aprender-se-á sempre com novas imagens. Estas imagens fazem-se nascer, metamorfoseiam-se, estão sempre numa vertigem de movimento criador. São elas mesmas movimentos preparatórios de uma imaginação ainda por decifrar. Têm uma amplitude sem tamanho, nem peso, nem contorno. Parecem ilusões e nem sequer são mágicas. Como não são lógicas, nem ilustrativas, nem narrativas. Não se deixam apanhar porque não cabem em espaços como o universal, a quantidade, a qualidade, a identidade, a semelhança, etc. $\mathrm{Na}$ sua variedade são impossíveis de catalogar. Parece mesmo que nem existem e no entanto, como refere Deleuze a propósito da Figura, "adquirem uma espécie de autonomia em face dos corpos: como num diagrama cujas linhas unissem somente sensações" (Deleuze, 1981, p. 124, tradução nossa).

Mesmo uma imagem em geral não se desliga nunca de dificuldades várias. Por um lado pode designar uma representação visual que descreve e simultaneamente esconde. Por outro, uma imagem designa também um conjunto mais complexo formado pela representação visual, o estado do corpo, os impulsos do ato que não podemos descrever e que acompanham toda a imagem. Ver uma imagem é, não somente, ser confrontado com uma representação dessa imagem, mas também experimentar emoções e desejos de aproximação e semelhança ou ao contrário de afastamento e estranheza.

Filosofia e Educação [rfe] - volume 8, número 1 - Campinas, SP

Fevereiro-Maio de 2016 - ISSN 1984-9605 - p. 26-37 
Deslocamo-nos por lugares que correspondem a imagens, sonhamos com imagens, pensamos com elas e sem elas. A imagem pode ser a mediação, o laço, a transição, a comunicação. Mas uma imagem é também terra desconhecida, primeiro rosto e diagrama do mundo. Pode dizer-se que a imagem é o mais próximo do corpo (com tudo o que pode agenciar), ela é igualmente o mais distante e incomunicável, sem semelhança, a escapar-se e a deformar-se, a dissipar-se, a transformar-se e a traduzir-se em palavras insuficientes para a dizer ou a transportar-se em tecnologia incapaz de a transferir. A imagem, mesmo se a consideramos do lado da representação, é um excesso material, físico e psíquico que apresenta grandes diferenças relativamente ao objecto de partida.

A nossa hipótese propõe uma outra abordagem. A imagem enquanto processo intraduzível, indiscernível, trabalho preparatório inconsciente, é espaço potencial, operador de devires e acasos, criador de afectos, com implicações em todos os campos do conhecimento, das artes, da vida quotidiana. A imagem enquanto operação, transformadora prática de energias, "ergue-se" e é capaz de se subtrair à própria imagem.

Quando se começa a imaginar assim, a ser, a sentir, a vida torna-se real e aprende-se - os afectos são sempre vivos e intensos. A vida acontece numa amplitude $=\mathrm{x}$ correndo o risco de nunca ser realmente descoberta. É uma "catástrofe" que nas condições mais favoráveis não produz uma "catástrofe". Como estas imagens! Que usam do seu direito de não comunicarem. Habitam, pois, essa zona de perturbação em que, como diz Winnicott, "estar-se escondido é um prazer, mas é uma catástrofe não se ser descoberto" (Winnicott, 1989, p. 160, tradução nossa).

As crianças, os adolescentes, os artistas como o nadador "aprendem" logo, em intensidade e em grande velocidade, porque, justamente, habitam essas zonas e são criadores destas imagens, estão sozinhos com elas. Usam a

Filosofia e Educação [rfe] - volume 8, número 1 - Campinas, SP

Fevereiro-Maio de 2016 - ISSN 1984-9605 - p. 26-37 
"familiaridade prática" para recusarem as outras imagens, fazem, diz Winnicott, "um uso são da não comunicação" (Winnicott, 1989, p. 158, tradução nossa). E fazem com estas essa singular espera ou repouso incomunicável que se traduz numa revindicação do direito de assim continuar a existir. São seres capazes das maiores velocidades como das maiores lentidões e para eles "a comunicação estabelece-se sem que possamos dizer que o estado do objecto é subjectivo ou percebido objectivamente" (Winnicott, 1989, p. 158, tradução nossa). São capazes de viver positivamente o dilema: da "necessidade urgente de comunicar e a necessidade ainda mais urgente de não ser encontrado" (Winnicott, 1989, p. 158, tradução nossa). E daí mesmo ergue-se a imagem, a imagem sem imagem.

Imagens-corpo virtuais a atualizarem-se em cada criação singular, feitas de matéria sempre mutável que transporta e torna sensíveis as forças que se exprimem nas formas. E são sempre problemáticas. Não se desligando da questão de como construi-las. O que leva Bacon a perguntarse: "como é que eu sinto que posso fazer esta imagem mais imediatamente real para mim mesmo?” (Deleuze, 1981, p. 87, tradução nossa).

Para as imagens comuns, a multiplicação e proliferação torna bem difícil a sua definição. As imagens estão por todo lado, como a vida. Tornam-se contagiantes, usamo-las e temos alguma dificuldade em dizer o que são exatamente. Estamos rodeados por elas, interagimos com elas, modelam-nos e deformam-nos os corpos. E não parecem nunca asseguradas ou definitivas. Superfícies sedutoras, e simultaneamente impenetráveis, subversivas, transgressoras, dogmáticas, banais, cópias, alegorias. Pretendentes a uma presença que substitui o próprio original mesmo quando ele nem existe. Agentes eficazes, que supostamente entram num jogo sem fim de dar a ver e a esconder, reenviam a referentes ou não. São coisas,

Filosofia e Educação [rfe] - volume 8, número 1 - Campinas, SP

Fevereiro-Maio de 2016 - ISSN 1984-9605 - p. 26-37 
signos, índices, símbolos, ícones, imagens de qualquer coisa, têm propriedades de aparência mágica como a figura do joker nas cartas de baralho; são presenças reais e irreais, visíveis e invisíveis. Mas, tornadas ilocalizáveis põem problemas e levadas ao seu extremo abalam as certezas, desestruturam, caotizam, tornam-se susceptíveis na sua relação com o aleatório, o acaso, o caos. Quando conjugam elementos-partículas heterogêneos e perdem os clichês, não são mais imagens sem devires nem forças. Deixam de ser imagens comuns, são imagens sem imagem. Quando conjugam "pontos relevantes do nosso corpo" com "multiplicidades de fulgores" tornam-se imagens-afecto, variações puras que se atualizam a cada instante, na criação, a cada corte ou conjugação no caos - o que tem lugar acontece nesse espaço-tempo destas imagens. São elas então que dão que pensar e são muito concretamente inimagináveis, impensáveis e irrepresentáveis. As artes como as aprendizagens em geral são incansáveis a criar estas imagens. O senso comum procura incessantemente forjá-las, mimetizá-las, representando-as.

Multiplicidades desterritorializadas e desterritorializantes, espaços lisos estendidos numa linha de variação, são imagens-afecto que fazem a passagem viva de intensidades, forças e devires. O corpo afectivo torna-se, com estas imagens, concreta passagem de sensações. Aprende-se realmente com o encontro de cada vez originário, familiar e prático, com o mundo. $\mathrm{O}$ nadador voltará a nadar, volta-se a dançar, como se volta sem cessar a pensar. 


\section{Referências}

DELEUZE, Gilles. Diferença e repetição. Lisboa: Relógio d’Água, 2000.

Dialogues (com Claire Parnet). Paris: Flammarion, 1996.

. Deux Régimes de Fous. Paris: Minuit, 2003.

. Critique et clinique. Minuit, 1993.

. Proust et les signes. Presses Universitaires de France, 1996.

. Francis Bacon - Logique de la sensation. Paris: La Différence, 1981.

WINNICOTT, Donald. Processus de maturation chez l'enfant. Paris: Payot, 1989. 